\title{
Functional analysis of upstream regulating regions from the Yarrowia lipolytica XPR2 promoter
}

\author{
Catherine Madzak, Sylvie Blanchin-Roland, \\ Ricardo R. Cordero Otero and Claude Gaillardin
}

Laboratoire de Génétique Moléculaire et Cellulaire INRA-CNRS, Centre de Biotechnologies AgroIndustrielles, Institut National Agronomique Paris-Grignon, 78850 Thiverval-Grignon, France
Author for correspondence: Catherine Madzak. Tel: +331308154 41. Fax: + 33130815457. e-mail:madzak@cardere.grignon.inra.fr

The XPR2 gene from Yarrowia lipolytica encodes an inducible alkaline extracellular protease. Its complex regulation involves $\mathrm{pH}$, carbon, nitrogen and peptones. Two previously identified upstream activating sequence (UAS) regions were analysed in a reporter system, outside the XPR2 context. Fragments from the UAS regions were inserted upstream of a minimal LEU2 promoter directing the expression of a reporter gene. The activity of the hybrid promoters was assessed following integration into the $Y$. lipolytica genome. This study confirmed the presence of two UASs composed of several interacting elements. Within the distal UAS (UAS1), a TUF/RAP1 binding site exhibited a UAS activity, which was enhanced by the presence of two adjacent repeats, overlapping sites similar to the CAR1 upstream repressing sequence from Saccharomyces cerevisiae. Within the proximal UAS (UAS2), the UAS activity required the interaction of both an ABF1-like binding site and a decameric repeat, containing Aspergillus nidulans PacC site consensus sequences. This decameric repeat was able to mediate repression due to carbon and/or nitrogen sources as well as pH-dependent activation. A study in the context of trans-regulatory mutations in the Y. lipolytica RIM101 gene showed that the PacC-like sites, potential binding sites for YIRim101p, were implicated in the derepression of UAS2-driven expression at neutral-alkaline pH. The in vivo response of the PacC-like decamers to external pH was dependent on the status of the pH-regulated activator YIRim101p, which is homologous to the $A$. nidulans PacC regulator. The carbon/nitrogen regulation imposed on the decamers was shown to be independent of YIRim101p and to override its effects.

Keywords: Yarrowia, XPR2, UAS, regulation, promoter

\section{INTRODUCTION}

The initiation and regulation of transcription in eukaryotes has been extensively studied, especially in yeast (reviewed by Struhl, 1987; Guarente \& Bermingham-McDonogh, 1992; Ptashne \& Gann, 1997). The cis-acting elements involved in the regulation of gene expression often consist of an association of multiple sites, binding different interacting transcription factors (reviewed, for Saccharomyces cerevisiae, by

Abbreviations: AEP, alkaline extracellular protease; DMS, dimethylsulphate; UAS, upstream activator sequence; URS, upstream repression sequence.
Svetlov \& Cooper, 1995). In yeast cells, upstream activation sequences (UASs) are necessary for transcription. They function in either orientation and at a variable distance with respect to the TATA box and transcription start site. In contrast to enhancers in higher eukaryotes, they are found essentially upstream from these basal elements, although several exceptions have been reported (Fantino et al., 1992; Sinclair et al., 1994). UASs are targets for transcriptional activators, whose binding can be either induced by physiological conditions, or constitutive. In the latter case, their activity can be regulated by another protein (for example, via phosphorylation, as was shown for the $S$. cerevisiae general transcription factor ABF1 by Trawick 
et al., 1992). Although most cases of repression in yeast seem to result from inactivation or absence of transcription factors, some negative regulatory sites, or upstream repression sequences (URSs), have been identified (Luche et al., 1990; Ronne, 1995; Gailus-Durner et al., 1997). The repressors binding these sites could exert their effect by interacting either directly with basal transcription factors or with activator proteins (HannaRose \& Hansen, 1996). In some cases, a single protein may, in different contexts, display either activating or repressing activity (Ozcan et al., 1996; Rubin-Bejerano et al., 1996). This is in particular the case for the $S$. cerevisiae general transcription factor RAP1 (Drazinic et al., 1996), for which the two activities have been separated in some mutants (Sussel \& Shore, 1991). The existence of co-activator and co-repressor proteins, that bridge the interaction of an activator or of a repressor with its ultimate target, has also been reported (Guarente, 1995; Hanna-Rose \& Hansen, 1996; Stargell \& Struhl, 1996).

Yarrowia lipolytica is a dimorphic yeast with high secreting capacities (Barth \& Gaillardin, 1996). The $X P R 2$ gene from $Y$. lipolytica encodes an inducible alkaline extracellular protease (AEP) which is the major protein secreted by this yeast (Ogrydziak et al., 1977; Davidow et al., 1987). The XPR2 promoter (pXPR2) has been used to direct heterologous protein production in Y. lipolytica (Franke et al., 1988; Nicaud et al., 1989a, 1991; Tharaud et al., 1992; Hamsa \& Chattoo, 1994; Park et al., 1997) but its complex regulation hinders its industrial use. Derepression of AEP occurs at $\mathrm{pH}$ above 5.5 on media lacking preferred carbon and nitrogen sources; full induction of the $\mathrm{pXPR} 2$ requires high levels of peptones in the culture medium, although the exact nature of the inducer is unknown (Ogrydziak et al., 1977). The functional $\mathrm{pXPR} 2$ encompasses roughly $800 \mathrm{bp}$ (Davidow et al., 1987). Thus, for both fundamental and practical reasons, we undertook to identify some of the cis-acting elements which participate in the complex regulation of $\mathrm{pXPR} 2$.

Deletion analysis of $\mathrm{pXPR2}$ evidenced two major UASs essential for promoter activity (Blanchin-Roland et al., 1994). In vivo genomic DMS footprints demonstrated that several sequences within each UAS interacted with proteins. No difference was found between binding patterns under inducing or repressing conditions, suggesting that the activity of the bound transcription factors was modulated by other regulatory proteins, or that different factors bound the same sequence under different conditions (Blanchin-Roland et al., 1994).

Further studies of regulatory mutants affecting the synthesis of Y. lipolytica extracellular proteases (AEP and the acidic protease AXP) led to the identification of YIRim101p (Lambert et al., 1997). This protein of the $\mathrm{His}_{2} \mathrm{Cys}_{2}$ zinc finger family is homologous to the transcriptional activators Rim $101 \mathrm{p}$ of $S$. cerevisiae, required for the entry into meiosis, and $\mathrm{PacC}$ of Aspergillus nidulans, Aspergillus niger and Penicillium chrysogenum, which mediate regulation by ambient $\mathrm{pH}$.
YlRim101p is essential for mating and sporulation, and for AEP derepression. In A. nidulans, the model for $\mathrm{pH}$ regulation assumes that, at ambient neutral-alkaline $\mathrm{pH}$ (which is sensed by a cascade of $P A L$ genes; Arst et al., 1994), the PacC protein becomes a substrate for an unidentified protease that removes $60 \%$ of the polypeptide from its C-terminus (Orejas et al., 1995). This proteolytic event converts $\mathrm{PacC}$ into a functional form able to activate the transcription of genes expressed at alkaline $\mathrm{pH}$, and to repress genes expressed at acidic $\mathrm{pH}$. This model seems to apply also to YlRim101p (Lambert et al., 1997). Indeed, a potential proteolytic site is present in the protein; a C-terminally truncated version of YlRim101p acts as a dominant suppressor of pal mutations in Y. lipolytica and it activates XPR2 expression independently of ambient $\mathrm{pH}$ (Lambert et al., 1997). Furthermore, two highly conserved PacC binding sites were found in one of the XPR2 UASs, and were shown to be bound by protein(s) in vivo (BlanchinRoland et al., 1994).

In this study, we wished to define more precisely the contribution of each UAS to the activity of the $\mathrm{pXPR2}$ and to specify the contribution of the putative $\mathrm{PacC} /$ Rim101p targets to its regulation. In order to avoid potential compensation or position effects which may occur with the whole promoter, we developed a new reporter system. Several DNA fragments from each UAS region were used to construct hybrid promoters, in order to analyse their physiological activity outside the $X P R 2$ context. They were inserted in front of a minimal LEU2 promoter directing the expression of the lac Z gene. The activity of the hybrid promoters was assessed, following integration into $Y$. lipolytica genome, under different physiological conditions. We also checked the activity of some of our hybrid promoters, in strains carrying different mutations in YlRIM101 (namely a null mutation or an activating C-terminal truncation), in order to separate the different regulations that act upon each UAS.

\section{METHODS}

Plasmids. Plasmids used are described in Table 1. New constructs and mutated plasmids were screened by restriction analysis or PCR, then confirmed by DNA sequencing.

Plasmids with hybrid promoters. The pINA781 reporter plasmid (see Fig. 2) was constructed by replacing the SphIBamHI fragment from pINA354 with a DNA fragment obtained by $S p h \mathrm{I} / \mathrm{Bam} \mathrm{HI}$ digestion of a PCR product synthesized from pINA354 and the following two mutagenic oligonucleotides : $5^{\prime}$ TCTTGGgaTcCTTAGTTTCGGGTTCCAT $3^{\prime}$ and $5^{\prime}$ GGTTTAGgCaTgCACtgAtCACGGGCAAAAGTGCGT 3' (lower-case letters indicate mutations creating the underlined restriction sites, respectively: $B a m \mathrm{HI}$, $S p h I$ and $B c l I$ ).

The derivatives of pINA781 were constructed by insertion at the SphI site of the following DNA fragments. 'UAS1A' was obtained by hybridization of the two following oligonucleotides : 5 ' CCTGAGGTGTCTCACAAGTGCCGTGCAGTCCGCATG $3^{\prime}$ and 5' CGGACTGCACGGCACTTGTGAGACACCTCAGGCATG 3' (SphI cohesive ends under- 


\section{Table 1. Plasmids used}

The plasmids with hybrid promoters, carrying various fragments of $\mathrm{pXPR} 2$ (described in Methods) inserted at the SpbI site of pINA781, are described in Table 2. In some of these plasmids, the LEU2 marker gene was replaced by the URA3 marker gene, as explained for pINA1272: they are described in Table 3.

\begin{tabular}{|c|c|c|}
\hline Plasmid & Relevant features & Reference or source \\
\hline pINA303 & $\begin{array}{l}\text { ClaI-XbaI fragment of Y. lipolytica XPR2 gene } \\
\text { (XPR2 promoter and prepro region) in } \\
\text { pBSKS + }\end{array}$ & Fabre et al. (1991) \\
\hline pINA918 & $\begin{array}{l}\text { Replacement into pINA } 303 \text { of the } A p a \mathrm{I}-E c o \mathrm{RV} \\
\text { fragment by an } A p a \mathrm{I}-E c o \mathrm{RV} \text { fragment } \\
\text { synthesized from } \mathrm{pXPR} 2 \text {, using PCR-directed } \\
\text { mutagenesis to change the pXPR2 TATA box } \\
\text { into a } S p h \mathrm{I} \text { site }\end{array}$ & This work \\
\hline \multicolumn{3}{|l|}{$\begin{array}{l}\text { The following } \\
\text { plasmids are } \\
\text { pBR322-based: }\end{array}$} \\
\hline pINA354 & $\begin{array}{l}\text { Integrative plasmid bearing Y. lipolytica LEU2 } \\
\text { gene; translational fusion [pXPR } 2:: \text { lacZ]; fully } \\
\text { functional XPR2 promoter, downstream from } \\
S p h \mathrm{I} \text { site; creation of a } S m a \text { l site instead of the } \\
\text { EcoRV site }\end{array}$ & $\begin{array}{l}\text { Blanchin-Roland et } \\
\text { al. (1994) }\end{array}$ \\
\hline pINA404 & $\begin{array}{l}\text { Integrative plasmid bearing Y. lipolytica } L E U 2 \\
\text { gene; translational fusion }[\mathrm{p} X P R 2:: l a c Z] \text {; fully } \\
\text { functional XPR2 promoter, downstream from } \\
M l u I \text { site; deletion of the EcoRV site }\end{array}$ & $\begin{array}{l}\text { Blanchin-Roland et } \\
\text { al. (1994) }\end{array}$ \\
\hline pINA781 & $\begin{array}{l}\text { Reporter plasmid with translational fusion } \\
\text { [minimal pLEU2::lacZ]; SphI-BamHI fragment } \\
\text { carrying minimal LEU2 promoter (TATA box } \\
\text { and ATG region from nucleotide }-94 \text { to }+18 \text {; } \\
\text { restriction sites created by PCR-directed } \\
\text { mutagenesis) replacing the same fragment } \\
\text { carrying pXPR2 into pINA354; the } S p h \mathrm{I} \text { site } \\
\text { allows insertion of DNA fragments upstream of } \\
\text { minimal pLEU2 (Fig. 2) }\end{array}$ & This work \\
\hline pINA919 and 920 & $\begin{array}{l}\text { Insertion into pINA781 of the } S p h \text { I fragment } \\
\text { from pINA918, carrying the whole functional } \\
\text { XPR2 promoter devoid of its TATA box, in } \\
\text { direct and inverted orientation, respectively }\end{array}$ & This work \\
\hline pINA311 & $\begin{array}{l}\text { Replicative plasmid bearing } A R S 18, U R A 3 \text { and } \\
\text { XPR2 genes from Y. lipolytica }\end{array}$ & $\begin{array}{l}\text { Cordero Otero \& } \\
\text { Gaillardin (1996) }\end{array}$ \\
\hline pINA1272 & $\begin{array}{l}\text { Derivative of pINA781, in which the KpnI-AseI } \\
\text { fragment carrying the } L E U 2 \text { marker gene was } \\
\text { replaced by the corresponding fragment from } \\
\text { pINA311, carrying the } U R A 3 \text { marker gene }\end{array}$ & This work \\
\hline
\end{tabular}

lined). 'UAS1B' was obtained by $S p h I$ digestion of a PCR product synthesized from pINA354 and the following two mutagenic oligonucleotides: 5' ATCAGGTgCAtgCTGAGGTGTCTCACAAGTGC $3^{\prime}$ and $5^{\prime}$ ATGCATAGcAtgCCGGATCGAGGTGGGCGG 3' (lower-case letters indicate mutations creating the underlined $S p h \mathrm{I}$ restriction sites). 'UAS2A', 'UAS2B' and 'UAS2C' were obtained respectively by hybridization of the following pairs of oligonucleotides: $5^{\prime}$ CGGCCAAGCTTCATCGTCTTGGCGCGTCTTGGCGAGAAGCTTGCATG $3^{\prime}$ and 5' CAAGCTTCTCGCCAAGACGCGCCAAGACGATGAAGCTTGGCCGCATG $3^{\prime} ; 5^{\prime}$
CATCGTCTTGGCGCGTCTTGGCGAGAGCCGTGTTTCGTGACGCATG $3^{\prime}$ and 5' CGTCACGAAACACGGCTCTCGCCAAGACGCGCCAAGACGATGCATG $3^{\prime} ; 5^{\prime}$ CAGAGCCGTGTTTCGTGACGCATG $3^{\prime}$ and $5^{\prime}$-CGTCACGAAACACGGCTCTGCATG 3' (SphI cohesive ends underlined). 'MutGCN' and 'MutABF' were obtained by $S p h I$ digestion of two PCR products synthesized from pINA354 with the same upstream mutagenic oligonucleotide: 5' GATAATGcatGCATCGTCTTGGCGC 3' (lower-case letters indicate mutations creating the underlined $S p h$ I restriction site) and two downstream mutagenic oligonucleotides, 
respectively: 5' TGCTCTGcaTGCGTCACGAAACCGTGCTCTCGCCAAG 3' (mutations indicated in bold-face type destroy the homology to the consensus ABF1 binding site of S. cerevisiae: 5' GTCACGAAACACG 3') or 5' GAAACTGgcaTGcTAAGGTCACGAAACACGGCTC $3^{\prime}$ (mutations indicated in bold-face type destroy the homology to the consensus GCN4 binding site of $S$. cerevisiae : 5'-TTGCGTCAC).

The plasmid pINA918, providing the $S p h$ I fragment carrying the whole $\mathrm{pXPR} 2$ devoid of its TATA box, was obtained by replacing the ApaI-EcoRV fragment from pINA303 with a DNA fragment obtained by ApaI-EcoRV digestion of a PCR product synthesized from pINA303 with the following two oligonucleotides: 5' TCAACGGGCCCGTCGATGGGGTgcATgcCGTGTTTCTGGAC $3^{\prime}$ (lower-case letters indicate mutations creating the underlined $S p h \mathbf{I}$ restriction site replacing the TATA box; the ApaI restriction site is also underlined) and 5' ACCATGTTTCAGCGCAATCCGACTTCCAACCC 3' (located downstream of the EcoR V restriction site).

Some of the plasmids with hybrid promoters (pINA781 and derivatives with two direct copies of respectively 'UAS1B', 'UAS2A' and 'UAS2B' fragments) were modified for use with the LAM100 and AM319AC strains, by replacing the LEU2 marker gene by the URA3 one (resulting plasmids: pINA1272 and respectively pINA1273, 1274 and 1275): the KpnI-AseI fragment from these plasmids (carrying the XPR2 terminator, LEU2 gene and $\mathrm{pBR}$ sequence) was replaced by the corresponding fragment from pINA311 (carrying the XPR2 terminator, URA3 gene and $\mathrm{pBR}$ sequence).

Plasmids carrying mutations within pXPR2. Deletions and/or mutations in $\mathrm{pXPR2}$ were constructed by the method of Kunkel et al. (1987), using pINA303 as a template.

To generate deletions of GCN4-like sites, the following oligomers were used: 5' CTGCACGGCACTGATCAGATTGTACC $3^{\prime}$ (deletion from -800 to -792 within UAS1: $\triangle$ GCN4-1), introducing a Bcll site (underlined); $5^{\prime}$ AACTGCTCTGATAAGGTCACGAAACAC $3^{\prime}$ (mutations indicated in bold-face type destroy the site within UAS2: MutGCN4-2 - same mutations as in the 'MutGCN' fragment) and $5^{\prime}$ TGGTGTTGTGAAGCT'TCAAAGTCGGTTC $3^{\prime}$ (deletion from -288 to -280 between the two UASs: $\Delta$ GCN4-3), introducing a HindIII site (underlined).

To generate deletions of each of the imperfect repeats of the UAS1 region, oligomers $5^{\prime}$ CAAAGAGAAGCAAGGACTGCACGGCAC $3^{\prime}$ and $5^{\prime}$ CCCCGGATCGGAACAACGGTC $3^{\prime}$ were used to delete from position -775 to $-767(\Delta \mathrm{IR} 1)$ and -717 to -708 ( $\Delta \mathrm{IR} 2$ ), respectively.

All these deletions were then transferred to pINA404 as follows : the $[N h e \mathrm{I}-B s m \mathrm{I}]$ fragment carrying $\Delta \mathrm{GCN} 4-1$ or $\Delta \mathrm{IR} 1$ or $\Delta \mathrm{IR} 2$, and [NheI-PstI] and [PstI-BsmI] fragments, both from pINA404, were recombined; the [ApaI-PvuI] fragment carrying MutGCN4-2 or $\Delta$ GCN4-3, and [ApaI (partial)-PstI] and $[P s t \mathrm{I}-P v u \mathrm{I}]$ fragments, both from pINA404, were recombined.

To delete the three GCN4-like sites all together, first the [NheI-EcoRV] fragment carrying $\Delta \mathrm{GCN} 4-3$ was ligated into the plasmid carrying MutGCN4-2 cleaved by the same enzymes. Then the [PvuI-ApaI $]$ fragment carrying both mutations was recombined with the $[P v u \mathrm{I}-P s t \mathbf{I}]$ fragment carrying $\Delta$ GCN4-1 and with the $[P s t I-A p a I$ (partial) $]$ fragment from pINA404.

To delete both imperfect repeats of the UAS1 region, the [MluI-SnaBI (partial)] fragment carrying $\Delta \mathrm{IR} 1$ and the [SnaBI-BsmI] fragment carrying $\Delta \mathrm{IR} 2$ were recombined into
pINA303. Then the [NheI-BsmI] fragment carrying both deletions, and $[B s m I-P s t I]$ and $[$ Pst $I-N h e I]$ fragments, both from pINA404, were recombined.

Strains and transformation procedures. The bacterial strains used were Escherichia coli HB101 (Boyer \& RoullandDussoix, 1969) and DH5 $\alpha \mathrm{F}^{\prime}$ (Stratagene). E. coli was transformed as described by Hanahan (1985).

The Y. lipolytica strain used was JM23SB, previously obtained (Blanchin-Roland et al., 1994) by integrative transformation of JM23 (MatB leu2-35 lys5-12 ura3-18 xpr2::LYS5) with plasmid pINA300', providing a wildtype URA3 gene and a pBR322 platform useful for plasmid targeting. Plasmids pINA404, pINA781 and their derivatives were targeted to this docking platform by NotI digestion.

Two $Y$. lipolytica strains mutated in the trans-acting regulation pathway of XPR2 expression were also used. Strain LAM100 (MatA ura3 lys11 rim101-1018) carries a YlRIM101 null mutation (deletion of the zinc finger region, from codon 157 to 914 , and replacement by the LEU2 marker gene). This strain was obtained from the previously described LAM57 strain, carrying the null mutation Ylrim101-1018 and a URA3 marker at the XPR2 locus (see Fig. 1A of Lambert et al., 1997): $\mathrm{Ura}^{-}$clones were selected on 5-fluoroorotic acid medium and recombination events reconstituting the wild-type XPR2 locus were selected (loss of URA3 and $\mathrm{pXPR} 2$ : lacZ fusion; Blanchin-Roland, unpublished). Plasmids pINA1272 to 1275 were targeted by KpnI digestion to the terminator of the wildtype XPR2 locus of the LAM100 strain. Strain AM319AC (MatA ura3 lys11 RIM101-1119) carries a C-terminally truncated form of YlRim101p, which mimics the putative in vivo truncation by abutting codon 330 to the natural YlRIM101 terminator and is able to activate XPR2 expression regardless of ambient $\mathrm{pH}$ (Lambert et al., 1997). Strain AM319 $\triangle$ C already carries the pINA404 plasmid inserted at the XPR2 locus. The transformation of strain AM319 $\triangle \mathrm{C}$ by plasmids pINA1272 to 1275 was performed by a double crossing-over: a KpnI/DraIII digestion of the plasmids made it possible to direct the replacement of the genomic pINA404 region (XPR2 terminator, LEU2 gene, $\mathrm{pBR}$ sequence and $\mathrm{pXPR} 2$ ::lacZ) by the corresponding one from the pINA1272 (to 1275) plasmid (XPR2 terminator, URA3 gene, pBR sequence and hybrid promoter:: $\operatorname{lac} Z$ ).

$Y$. lipolytica integrative transformation and Southern blot checking of yeast transformants were done as previously reported (Hoffman \& Winston, 1987; Xuan et al., 1988).

Culture media, growth conditions and enzyme assays. The fully inducing medium (YPDm) contained $0.2 \%(\mathrm{w} / \mathrm{v})$ yeast extract, $0 \cdot 1 \%$ glucose and $5 \%$ proteose peptone in $50 \mathrm{mM}$ sodium phosphate buffer ( $\mathrm{pH} 6.8$; Nicaud et al., 1989b). When the effect of acidic $\mathrm{pH}$ was assayed, YPDm was buffered with $200 \mathrm{mM}$ sodium citrate buffer ( $\mathrm{pH} \mathrm{4.0)}$. The peptone-free medium YEg (Blanchin-Roland et al., 1994) contained 1\% yeast extract and $0.1 \%$ glucose in $50 \mathrm{mM}$ sodium phosphate buffer (pH 6.8). The peptone-free medium MMAm (BlanchinRoland et al., 1994) contained $200 \mathrm{mM}$ sodium phosphate buffer ( $\mathrm{pH} \mathrm{6.8)}$, glycerol $\left(10 \mathrm{~g} \mathrm{l}^{-1}\right)$ as a carbon source and ammonium sulfate $\left(2 \mathrm{~g} \mathrm{l}^{-1}\right)$ as a nitrogen source. For $\beta$ galactosidase assays, cultures were grown at $23^{\circ} \mathrm{C}$ and harvested at the beginning of the stationary phase, corresponding to an $\mathrm{OD}_{600}$ of about 14 in YPDm, and about 8 in MMAm and YEg media. The $\beta$-galactosidase activity was measured as previously described (Blanchin-Roland et al., 1994) and was normalized for the $\mathrm{OD}_{600}$ of the culture broth. 
For each construction, two or three independent transformants (checked for correct integration by Southern blotting) were assayed, at least in duplicate. Reproducibility was in the range of $\pm 5 \%$ between the duplicates and in the range of $\pm 10 \%$ between repeated experiments.

\section{RESULTS}

\section{Activity of hybrid promoters containing fragments from $\mathrm{p} X P R 2$, in different media}

In order to dissect functionally the UAS1 and UAS2 regions outside their original $\mathrm{pXPR} 2$ context, several DNA fragments were inserted into the control plasmid pINA781, upstream from a minimal LEU2 promoter directing the expression of the lacZ gene (Figs 1 and 2). The resulting plasmids were integrated into the genome of Y. lipolytica JM23SB, at the pBR322 platform; transformants were checked for being the result of a single integration event. The $\beta$-galactosidase activity of the integrants was measured in three media: YPDm, YEg and MMAm, all buffered at $\mathrm{pH} 6.8$. The native $\mathrm{pXPR} 2$ activity was maximum on peptone-containing YPDm; it was intermediate on the peptone-free YEg medium, and minimal on MMAm, which contains preferred carbon and nitrogen sources. Some constructions were also checked for a pH effect, on YPDm medium buffered at $\mathrm{pH} 4$, where native $\mathrm{pXPR} 2$ exhibited very low activity. The results are shown in Table 2.

Test of the reporter system. In order to validate our system, we inserted into pINA781 the whole pXPR2, devoid of its TATA box, in direct (pINA919) or inverted
(pINA920) orientation. The regulation pattern and range of activity exhibited by the strain carrying pINA919 were similar to those observed for the native pXPR 2 (Table 2, lines 3 and 1). The slight quantitative differences observed may reflect a contribution of the LEU2 TATA box. The results obtained with pINA920 (line 4) were similar except that the maximum activity, on YPDm, was twofold lower, probably reflecting the fact that the UAS2 region was less efficient in inverted orientation (see below). These results validate our reporter system since the $\mathrm{pXPR2}$ devoid of its TATA box was able to impose an XPR2-like regulation upon the minimal LEU2 promoter.

Analysis of the UAS1 region. The DNA fragment 'UAS1A' corresponds to position -805 to -776 of $\mathrm{pXPR} 2$; it carries a GCN4-like site and a sequence similar to the $\mathrm{UAS}_{\mathrm{RPG}}$ from S. cerevisiae (TUF/RAP1 binding site: see Vignais et al., 1990; Blanchin-Roland et al., 1994). The 'UAS1B' fragment corresponds to position -805 to -701 of $\mathrm{pXPR} 2$ and carries, in addition to 'UAS1A', an adjacent region encompassing two imperfect repeats, overlapping sites homologous to the URS $S_{\mathrm{CAR} 1}$ from $S$. cerevisiae. These four sequences (GCN4-like, $\mathrm{UAS}_{\mathrm{RPG}^{-}}$ like and repeats) were protected from DMS in vivo (Blanchin-Roland et al., 1994, and Fig. 1). Both fragments were able to promote an enhancement of activity on YPDm (and also on YEg and MMAm media for 'UAS1B') which was orientation-independent and increased with the number of copies. The 'UAS1A' fragment alone exhibited the properties of an UAS under non-repressing conditions (Table 2, lines 5 to 8), suggesting that the GCN4-like and/or the $\mathrm{UAS}_{\mathrm{RPG}^{-}}{ }^{-1 i k e}$

\section{UAS1}

UAS2

TGTCTC
ACA

DNA fragments from the promoter inserted in pINA781, upstream of the minimal LEU2 promoter:

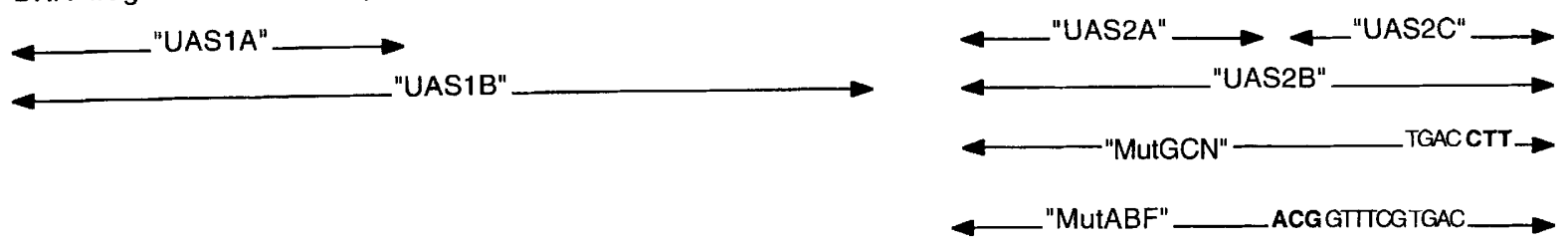

Fig. 1. Scheme of the UAS regions of pXPR2. The two regions of the distal UAS1 and the proximal UAS2 are represented. The sequences protected during DMS footprinting in vivo (Blanchin-Roland et al., 1994) are underlined with bold lines (only GC base pairs are tested by this method). The sequences homologous to known regulatory sites from $S$. cerevisiae or A. nidulans are underlined. The repeated sequences are underlined with dashed arrows. The DNA fragments used in the construction of the hybrid promoters are indicated. 
(a)

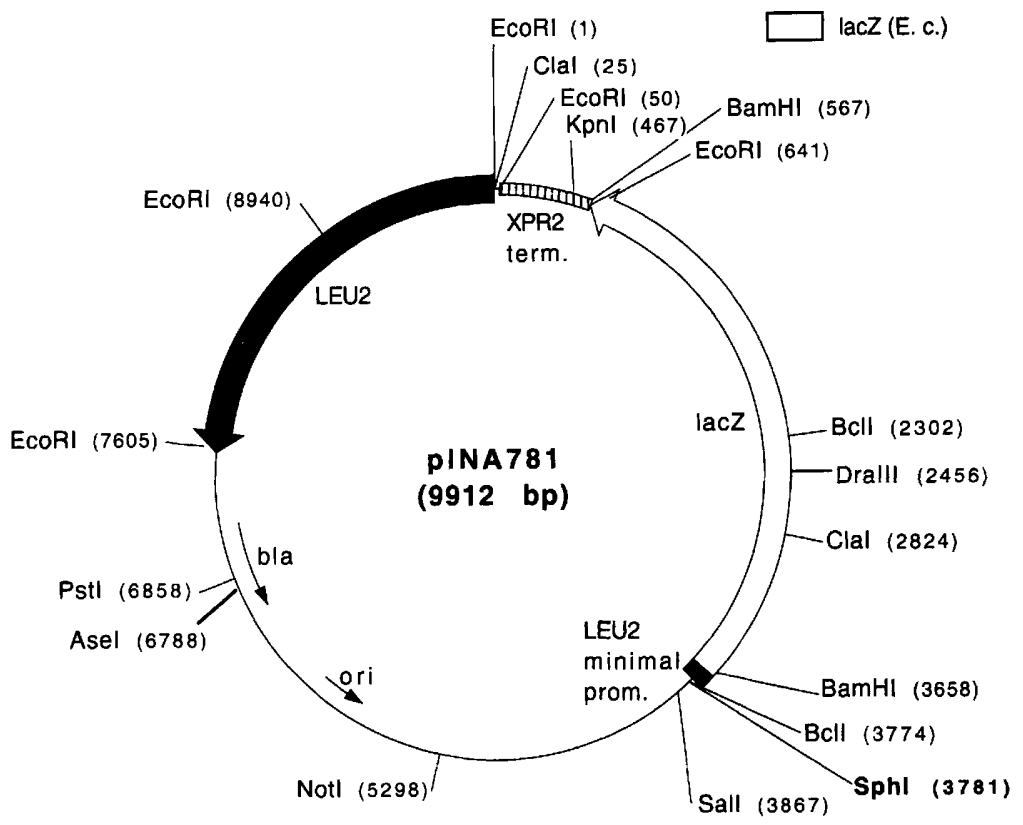

(b)

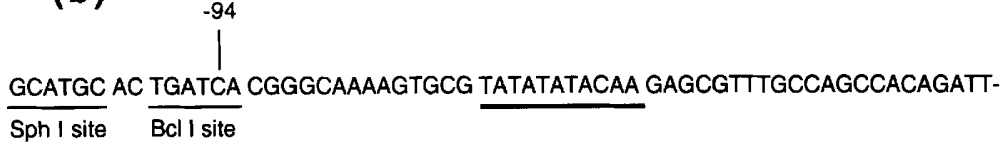

-TTCACTCCACACACCACATCACACATACAACCACACACATCCACA Á ATG GAA CCC GAa -
Fig. 2. The integrative pINA781 reporter plasmid. (a) Map of pINA781. The unique Sphl restriction site was used to introduce various DNA fragments from $p X P R 2$, upstream of the minimal LEU2 promoter directing the expression of the lacZ gene. The unique Notl restriction site was used to direct the integration of the plasmids obtained into the genome of $Y$. lipolytica strain JM23SB, at the pBR322 platform. (b) Fragment of sequence from pINA781 showing the minimal LEU2 promoter and the translational fusion with the $l a c Z$ reporter gene. The sequence conserved from the LEU2 promoter encompasses position -94 to +18 (in the numeration of the LEU2 gene). The TATA box and the ATG sequence are underlined in bold (Gaillardin \& Ribet 1987). ' $G T C$ ' is the first conserved codon from the $\beta$-galactosidase sequence and corresponds to the tenth codon of the lacZ gene. sequence were implicated in the UAS activity. This fragment did not mediate any sensitivity to $\mathrm{pH}$. The enhancement of activity was higher with 'UAS1B' (lines 9 to 12) than with 'UAS1A', showing that the added region also participates in the UAS effect. For the constructions carrying the 'UAS1B' fragment, activities on YPDm and YEg media were similar, showing that no peptone-sensitive element was present. The activities were at most threefold lower on MMAm and less than twofold lower on YPDm at $\mathrm{pH} 4$, but still well above those exhibited by the control plasmid pINA781 (line 2). Hybrid promoters containing this fragment are therefore poorly affected by environmental conditions (either carbon and/or nitrogen sources or acidic $\mathrm{pH}$ ), and appear to drive a quasi-constitutive expression.

Analysis of the UAS2 region. The DNA fragment 'UAS2A' corresponds to position -149 to -124 of $\mathrm{pXPR} 2$ and carries a decameric repeat, previously found to be protected from DMS in vivo (Blanchin-Roland et al., 1994). This repeat overlaps two sites identical (in inverted orientation) to the $A$. nidulans consensus $\mathrm{PacC}$ site: 5' GCCARG 3' (Tilburn et al., 1995; Suarez \& Peñalva, 1996). The fragment 'UAS2B' corresponds to position -150 to -106 of $\mathrm{pXPR} 2$; it carries, in addition to 'UAS2A', a site matching (in inverted orientation) the $S$. cerevisiae ABF1 site consensus (5' RTCRYBNNNNACG 3'; Della Seta et al., 1990a), and a partially overlapping GCN4-like site. The fragment 'UAS2C' corresponds to position -126 to -106 of $\mathrm{pXPR} 2$ and carries only these two last sites.

We first analysed the effects of these fragments on peptone (inducing) medium. The 'UAS2A' fragment was unable to activate the expression significantly in YPDm medium (Table 2, lines 13 to 16): the decameric repeat alone does not constitute an UAS. The 'UAS2B' fragment promoted a fivefold increase of activity in YPDm medium (line 17), and only a twofold one in the opposite orientation (line 18). A similar twofold activation, in inverted orientation, was reported for an ABF1 binding site from the $S$. cerevisiae TDH3 gene 
Table 2. Analysis of UAS1 and UAS2 regions: $\beta$-galactosidase activity of Yarrowia lipolytica strains carrying integrated plasmids with hybrid promoters, in different media

The results shown are the means of several experiments: for each construction, two or three independent transformants were assayed, at least in duplicate. $\beta$-Galactosidase activity is shown as units $\mathrm{ml}^{-1} \mathrm{~min}^{-1}$ per $\mathrm{OD}_{600}$ unit. The overall standard deviation was in the range of $\pm 10 \%$ between independent measurements. ND, Not determined.

\begin{tabular}{|c|c|c|c|c|c|c|}
\hline & \multirow[t]{3}{*}{ Plasmid } & \multirow[t]{3}{*}{ Promoter } & \multicolumn{4}{|c|}{$\beta$-Galactosidase activity in: } \\
\hline & & & \multirow{2}{*}{$\begin{array}{l}\text { Inducing } \\
\text { YPDm } \\
\text { medium }\end{array}$} & \multicolumn{2}{|c|}{ Peptone-free } & \multirow{2}{*}{$\begin{array}{c}\text { Acidic (pH 4) } \\
\text { YPDm } \\
\text { medium }\end{array}$} \\
\hline & & & & $\begin{array}{l}\text { YEg } \\
\text { medium }\end{array}$ & $\begin{array}{l}\text { MMAm } \\
\text { medium }\end{array}$ & \\
\hline 1 & pINA404 & $X P R 2$ native promoter & 303 & 70 & $1 \cdot 6$ & $5 \cdot 5$ \\
\hline 2 & pINA781 & Minimal pLEU2 & 11 & 20 & 20 & 11 \\
\hline \multicolumn{7}{|c|}{$\begin{array}{l}\text { Hybrid promoters with whole pXPR2, devoid of its TATA box, inserted into pINA781, } \\
\text { upstream of minimal pLEU2: }\end{array}$} \\
\hline 3 & pINA919 & 'pXPR2' $\rightarrow$ & 326 & 40 & $7 \cdot 4$ & 26 \\
\hline 4 & pINA920 & $\leftarrow$ 'pXPR2' & 146 & 31 & 14 & ND \\
\hline \multicolumn{7}{|c|}{$\begin{array}{l}\text { Hybrid promoters containing fragments from UAS1 region (inserted into pINA781, upstream of } \\
\text { minimal pLEU2): }\end{array}$} \\
\hline 5 & pINA791 & 'UAS1A' $\rightarrow$ & 17 & 19 & 11 & 21 \\
\hline 6 & pINA792 & $\leftarrow$ 'UAS1A' & 22 & ND & ND & ND \\
\hline 7 & pINA793 & 'UAS1A' $\rightarrow$ 'UAS1A' $\rightarrow$ & 52 & ND & 11 & 65 \\
\hline 8 & pINA794 & $\leftarrow$ 'UAS1A' $\leftarrow$ 'UAS1A' & 62 & 45 & 10 & ND \\
\hline 9 & pINA795 & 'UAS1B' $\rightarrow$ & 32 & 37 & 21 & 26 \\
\hline 10 & pINA796 & $\leftarrow$ 'UAS1B' & 44 & 57 & 28 & ND \\
\hline 11 & pINA797 & 'UAS1B' $\rightarrow$ 'UAS1B' $\rightarrow$ & 133 & 116 & 45 & 78 \\
\hline 12 & pINA798 & $\leftarrow$ 'UAS1B' $\leftarrow$ 'UAS1B' & 150 & 137 & 46 & ND \\
\hline \multicolumn{7}{|c|}{$\begin{array}{l}\text { Hybrid promoters containing fragments from UAS2 region (inserted into pINA781, upstream of } \\
\text { minimal pLEU2): }\end{array}$} \\
\hline 13 & pINA783 & 'UAS2A' $\rightarrow$ & 11 & $5 \cdot 3$ & $3 \cdot 2$ & $7 \cdot 7$ \\
\hline 14 & pINA784 & $\leftarrow$ 'UAS2A' & $9 \cdot 6$ & $5 \cdot 3$ & $3 \cdot 4$ & ND \\
\hline 15 & pINA785 & 'UAS2A' $\rightarrow$ 'UAS2A' $\rightarrow$ & 19 & $7 \cdot 4$ & $3 \cdot 0$ & $5 \cdot 2$ \\
\hline 16 & pINA786 & $\leftarrow$ 'UAS2A' $\leftarrow$ 'UAS2A' & 17 & $6 \cdot 2$ & $2 \cdot 9$ & ND \\
\hline 17 & pINA787 & 'UAS2B' $\rightarrow$ & 53 & 24 & 6 & 11 \\
\hline 18 & pINA788 & $\leftarrow$ 'UAS2B' & 19 & ND & ND & ND \\
\hline 19 & pINA789 & 'UAS2B' $\rightarrow$ 'UAS2B' $\rightarrow$ & 129 & 39 & $5 \cdot 4$ & 9 \\
\hline 20 & pINA790 & $\leftarrow$ 'UAS2B' $\leftarrow$ 'UAS2B' & 72 & 24 & $3 \cdot 4$ & 12 \\
\hline 21 & pINA913 & 'MutGCN' $\rightarrow$ & 57 & 15 & $5 \cdot 9$ & ND \\
\hline 22 & pINA915 & 'MutABF' $\rightarrow$ & 13 & $9 \cdot 2$ & $7 \cdot 4$ & ND \\
\hline 23 & pINA1047 & 'UAS2C' $\rightarrow$ & 23 & ND & 14 & 17 \\
\hline 24 & pINA1048 & $\leftarrow$ 'UAS2C' & 21 & ND & 15 & ND \\
\hline 25 & pINA1050 & $\leftarrow$ 'UAS2C' $\leftarrow$ 'UAS2C' & 21 & ND & $9 \cdot 4$ & 29 \\
\hline \multicolumn{7}{|c|}{ Hybrid promoters containing fragments from both UAS1 and UAS2 regions (inserted as above): } \\
\hline 26 & pINA910 & 'UAS1B' $\rightarrow$ 'UAS2B' $\rightarrow$ & 126 & 79 & 16 & 45 \\
\hline 27 & pINA907 & $\begin{array}{l}\leftarrow \text { 'UAS1B’ } \leftarrow \text { 'UAS2B' } \\
\text { 'UAS2B' } \rightarrow\end{array}$ & 341 & 104 & $9 \cdot 6$ & ND \\
\hline
\end{tabular}

(Jung et al., 1995). The increase was more than additive with two copies of 'UAS2B' (lines 19 and 20). The GCN4-like and/or the ABF1-like sites are therefore necessary for UAS activity. However, the 'UAS2C' fragment alone was unable to exhibit a significant UAS activity (lines 23 to 25), showing that the presence of the decameric repeat is also necessary for the UAS activity of the UAS2 region.
In order to define more precisely the role of GCN4-like and ABF1-like sites, we tested DNA fragments similar to 'UAS2B' in which either the GCN4-like site ('MutGCN') or the ABF1-like site ('MutABF') were modified using directed mutagenesis (cf. Methods and Fig. 1). The construction carrying the 'MutGCN' fragment (Table 2, line 21) exhibited activities similar to those of 'UAS2B' in the three media : the GCN4-like site 
is apparently not implicated in the UAS activity nor in its regulation. In contrast, the activity of the construction carrying the 'MutABF' fragment (line 22) was similar to that of the control plasmid on YPDm medium, suggesting that the ABF1-like site is necessary for UAS activity.

We then turned to peptone-free media. The constructions carrying the 'UAS2A' fragment exhibited a lower activity than the control plasmid on MMAm and YEg media (lines 13 to 16). This effect was reproducibly observed, but to a lesser extent, with the 'UAS2B' fragment (and with both 'MutGCN' and 'MutABF'), but not with the 'UAS2C' fragment (lines 23 to 25). This repressive effect can therefore be attributed to the sole decameric repeat.

Concerning pH (comparison of YPDm at $\mathrm{pH} 6.8$ and $\mathrm{pH} 4$ ), a slight diminution of activity was observed with 'UAS2A' under acidic conditions (Table 2, line 15), which was more pronounced with 'UAS2B' (line 17), and especially with two copies (lines 19 and 20), but was absent with 'UAS2C' (lines 23 and 25). This suggests that the decameric repeat, a supposed target of the RIM101/PacC regulator (Lambert et al., 1997), is indeed important for $\mathrm{pH}$ control. Note that the decameric repeat does not promote significant repression of the basal level of expression driven by the minimal LEU2 promoter (compare line 2 with lines 13-20 on YPDm $\mathrm{pH} 4$ ), but seems to be required for its induction at pH 6.8 on YPDm (see also below).

Reconstitution experiments. In order to test if the presence of both UAS1 and UAS2 upstream from the LEU2 basal promoter was sufficient to restore a regulatory pattern similar to that of the native XPR2 promoter, we inserted both 'UAS1B' and 'UAS2B' fragments into pINA781. As shown with pINA910 (Table 2, line 26), such a response was indeed observed since the lowest activity was measured on MMAm medium, whereas the highest was obtained on YPDm at $\mathrm{pH} 6.8$, as was the case for pINA919 (line 3: pXPR2 inserted into pINA781).

We fortuitously obtained a construct carrying one inverted copy of 'UAS1B' followed by two copies of 'UAS2B' (the first one inverted and the second one direct). A strain carrying this promoter exhibited, on YPDm and YEg media, activities comparable to those of the native $\mathrm{pXPR2}$ (pINA907, line 27, compared to line 1). The exact role of the intermediate copy of 'UAS2B' is not clear: it could bind itself to regulatory proteins, allowing their interaction with those bound to other fragments, or play essentially the role of a spacer sequence, allowing only a better interaction between regulatory proteins bound to 'UAS1B' and the direct copy of 'UAS2B'.

The activity on MMAm medium of the construction carrying pINA907 was lower than that of pINA910, and only slightly above those of constructions carrying two copies of the 'UAS2B' fragment (lines 19 and 20). This indicates that the decameric repeat from UAS2 region was able to shut down the expression driven by the UAS1 region.

\section{Activity of $\mathrm{pXPR2}$ carrying internal deletions or modifications, in different media}

In order to highlight the precise role of some potential sites within the whole $\mathrm{pXPR2}$, several internal deletions or modifications were performed in the $\mathrm{pXPR} 2$ region of pINA354, directing the expression of the lacZ gene. Some of the strains carrying these constructions have already been described by Blanchin-Roland et al. (1994) and were analysed further.

Deletion of the imperfect repeats of the UAS1 region. These sequences were identified previously (Blanchin-Roland et al., 1994) as protected from DMS in vivo and overlap sequences matching the consensus for the $\mathrm{URS}_{\mathrm{CAR} 1}\left(5^{\prime}\right.$ WVYCGCBND 3', determined by saturation mutagenesis by Luche $e t$ al., 1990), except that the upstream one exhibits a $\mathrm{C}$ at its $3^{\prime}$ border. Other sequences similar to $\mathrm{URS}_{\mathrm{CAR} 1}$ in the whole $\mathrm{pXPR2}$ are all in the inverted orientation and are more degenerate (except one, in the decamer region, as discussed below: see Discussion and Fig. 3). Each or both of the imperfect repeats of the UAS1 region were deleted from the whole $\mathrm{pXPR2}$ (nucleotides -775 to -767 and/or -717 to -708 : cf. Methods). The strains carrying these constructions exhibited levels of expression similar to those of the strain carrying pINA404 (wild-type pXPR2) on both YPDm and MMAm media (data not shown). This result contrasts with those obtained in the reporter system, where the region carrying the imperfect repeats (in the 'UAS1B' fragment) enhanced the activity of the core UAS1 (constituted by the 'UAS1A' fragment). It suggests that other regions, in the whole pXPR2, could be additionally involved in the regulation of the UAS1 activity and compensate for the loss of the imperfect repeats.

Deletion of the three GCN4-like sites of $p$ XPR2. Three DNA sequences ressembling the GCN4 binding site of $S$. cerevisiae (5' ATGACTCAT 3', core sequence underlined; Hill et al., 1986) are present in the pXPR2: in the UAS1 region (from nucleotide -800 to $-792: 5^{\prime}$ gTGtCTCAc $3^{\prime}$ ), in the region between the two UASs (from nucleotide -288 to $-280: 5^{\prime}$ gaGACTCAc $3^{\prime}$ ) and in the UAS2 region (from nucleotide -113 to -105 : $5^{\prime}$ gTGACgCAa $3^{\prime}$ ). These sites were deleted or mutated, either separately or all together, in the whole $\mathrm{pXPR} 2$ directing the expression of the lac $Z$ gene (cf. Methods). Strains carrying these constructs exhibited levels of expression similar to those of the wild-type $\mathrm{p} X P R 2$, in all three media (data not shown). None of the three sites therefore seems to be implicated in either the expression or the regulation of the XPR2 gene, under the conditions tested. This correlates with the reporter analysis, which showed that the GCN4-like site in the UAS2 region did not participate in the expression. It also indicates that, in the UAS1 region, the $\mathrm{UAS}_{\mathrm{RPG}}$ alone should constitute the core UAS.

Deletions in the UAS2 region: effect at different pHs. Although the results from Table 2 implicated the decameric repeat in the activation by neutral-alkaline $\mathrm{pH}$, it remained unclear if the low UAS2 activity at $\mathrm{pH} 4$ 
Table 3. Effect of YIRIM101 mutations on $\beta$-galactosidase expression directed by hybrid promoters, in different media

For each kind of hybrid promoter tested (minimal pLEU2 alone or with $\mathrm{pXPR2}$ fragments inserted at the SphI site), two plasmids are indicated: pINA781, 797, 785 and 789 carry the LEU2 gene and were integrated in strain JM23SB (same constructions as in Table 2); pINA1272-1275 are their derivatives carrying the URA3 gene and were integrated in strain LAM100 or AM319AC2. The genotype and status of the strains, concerning YlRIM101, are the following: JM23SB is RIM101+ (wild-type); LAM100 carries a null mutation rim101-1018 impairing the expression of XPR2 gene; AM319AC2 carries a C-terminal truncation leading to the activation of XPR2 expression, independently of ambient $\mathrm{pH}$ (Lambert et al., 1997). $\beta$-Galactosidase activity is shown as units $\mathrm{ml}^{-1} \mathrm{~min}^{-1}$ per OD 600 unit. The results are the means of at least three independent experiments and at least two transformants were assayed for each construction. The overall standard deviation was in the range of $\pm 10 \%$ between independent measurements.

\begin{tabular}{|c|c|c|c|c|c|c|c|c|c|c|}
\hline \multirow[t]{3}{*}{ Promoter (plasmid) } & \multirow[b]{3}{*}{$\begin{array}{l}\text { Strain ... } \\
\text { Genotype... } \\
\text { Status ... }\end{array}$} & \multicolumn{9}{|c|}{$\beta$-Galactosidase activity in: } \\
\hline & & \multicolumn{3}{|c|}{ Inducing YPDm medium $\mathrm{pH} 6.8$} & \multicolumn{3}{|c|}{ Acidic YPDm medium pH 4.0 } & \multicolumn{3}{|c|}{ Peptone-free MMAm medium } \\
\hline & & $\begin{array}{c}\text { JM23SB } \\
R I M^{+} \\
\text {wt }\end{array}$ & $\begin{array}{c}\text { LAM100 } \\
\operatorname{rim}-1018 \\
\operatorname{rim} \Delta Z f\end{array}$ & $\begin{array}{c}\mathrm{AM} 319 \Delta \mathrm{C} 2 \\
\text { RIM-1119 } \\
\text { RIMAC2 }\end{array}$ & $\begin{array}{c}\mathrm{JM} 23 \mathrm{SB} \\
R I M^{+} \\
\mathbf{w t}\end{array}$ & $\begin{array}{r}\text { LAM100 } \\
\operatorname{rim}-1018 \\
\operatorname{rim} \Delta Z f\end{array}$ & $\begin{array}{c}\text { AM319AC2 } \\
\text { RIM-1119 } \\
\text { RIMSC2 }\end{array}$ & $\begin{array}{c}\text { JM23SB } \\
\boldsymbol{R I M}^{+} \\
\text {wt }\end{array}$ & $\begin{array}{r}\text { LAM100 } \\
\operatorname{rim}-1018 \\
\operatorname{rim} \Delta Z f\end{array}$ & $\begin{array}{c}A M 319 \Delta C 2 \\
\text { RIM-1119 } \\
\text { RIMAC2 }\end{array}$ \\
\hline \multicolumn{2}{|l|}{$\begin{array}{l}\text { Minimal pLEU2 (pINA781 or } \\
\text { pINA1272) }\end{array}$} & 11 & 12 & 13 & 11 & 11 & 10 & 20 & 18 & 17 \\
\hline \multicolumn{2}{|l|}{$\begin{array}{l}\text { +'UAS1B' } \rightarrow \text { 'UAS1B' } \rightarrow \\
\text { (pINA797 or pINA1273) }\end{array}$} & 133 & 110 & 129 & 78 & 87 & 93 & 45 & 31 & 31 \\
\hline \multicolumn{2}{|l|}{$\begin{array}{l}+ \text { +UAS2A' } \rightarrow \text { 'UAS2A' } \rightarrow \\
\text { (pINA785 or pINA 1274) }\end{array}$} & 19 & 3.7 & 27 & $5 \cdot 2$ & $3 \cdot 5$ & 19 & 30 & 2.9 & $3 \cdot 9$ \\
\hline \multicolumn{2}{|l|}{$\begin{array}{l}+ \text { +UAS2B' }^{\rightarrow} \text { 'UAS2B' } \rightarrow \\
(\text { (pINA789 or pINA1275) }\end{array}$} & 129 & 11 & 98 & 9 & 11 & 71 & $5 \cdot 4$ & $5 \cdot 5$ & $7 \cdot 4$ \\
\hline
\end{tabular}

reflected an absence of activation or a repression effect, the values being close to the activity of the control promoter. In order to clarify this point, we tested some strains carrying deletions in the $\mathrm{pXPR} 2$ at different $\mathrm{pHs}$.

A deletion of the decameric repeat (from position -154 to -124$)$ was previously shown to lead to a residual activity of $13-15 \%$ in the three media, at $\mathrm{pH} 6.8$ (Blanchin-Roland et al., 1994). The additional deletion of the ABF1-like site (and overlapping the GCN4-like site) did not decrease the activity further (from position -154 to -104 : residual activity of $14 \%$ in YPDm medium), showing that the deletion of the decamers was sufficient to inactivate totally the UAS2 (BlanchinRoland et al., 1994). This result correlates with those of the reporter system.

These two deleted strains were tested for a $\mathrm{pH}$ effect. The strains carrying the deletion of the decamers, alone or together with adjacent sites, exhibited an activity on YPDm at $\mathrm{pH} 4$ similar to that of the wild-type $\mathrm{pXPR} 2$ (4 units, instead of 3 units for pINA404). If the decamers were the target for a repressor under acidic conditions, an increase of activity at $\mathrm{pH} 4$ should have been obtained for the deleted strains, compared to the wild-type. The fact that no difference was observed is in favour of the hypothesis that decamers mediate only activation under neutral-alkaline conditions on YPDm.

\section{Effect of YIRIM101 mutations on the activity of hybrid promoters}

The results in Table 2 suggested that the decamers were able to mediate both activation in response to neutralalkaline $\mathrm{pH}$, and repression in response to the preferred carbon and nitrogen sources. In an attempt to separate these effects, we analysed some of the hybrid promoters in strains carrying mutated versions (inactive or constitutively active) of the $\mathrm{pH}$-responsive transcriptional activator YlRim101p. In order to allow their selection in the YlRIM101-mutated strains, we exchanged the LEU2 for the URA3 marker in the plasmids pINA781 (control minimal pLEU2), pINA797 (two direct copies of 'UAS1B'), pINA785 (two direct copies of 'UAS2A') and pINA789 (two direct copies of 'UAS2B'). This modification preserved the overall structure of the resulting plasmids, respectively pINA1272 to 1275 . These plasmids were integrated into the genome of strain LAM100 carrying a null mutation of YlRim 101p (deletion of the zinc finger region, denoted rim $\Delta Z f$, and of the strain AM $319 \Delta \mathrm{C}$ carrying a Cterminal truncation (RIM $\Delta C 2)$ which renders the YlRim101p constitutively functional, independently of ambient $\mathrm{pH}$ (Lambert et al., 1997). The results observed in different media are shown in Table 3.

The levels of $\beta$-galactosidase expression driven by the minimal pLEU2 or by the hybrid promoter with 'UAS1B' fragments were independent of the YIRIM101 context, on all the media tested (YPDm medium at $\mathrm{pH} 6.8$, YPDm medium at $\mathrm{pH} 4$ and MMAm medium). Thus, the YlRIM101 context does not modify the UAS1driven expression, neither at different $\mathrm{pHs}$, nor in the presence of preferred carbon and nitrogen sources.

In contrast, the hybrid promoters with 'UAS2A' fragments (decamers containing PacC-like sites) or with 'UAS2B' fragments (decamers and ABF1/GCN4-like sites) exhibited, in the YPDm medium buffered at $\mathrm{pH} 6.8$ or at $\mathrm{pH} 4$, activities strongly dependent on the YlRIM101 context. In the rim $A Z f$ context (LAM100), the activities were, for both ambient $\mathrm{pHs}$, in the same 
range as those exhibited at $\mathrm{pH} 4$ in the wild-type context (and markedly reduced compared to those observed at $\mathrm{pH} 6.8$ in the wild-type context). In the C-terminally truncated RIM $\Delta$ C2 context (AM $319 \Delta \mathrm{C}$ ), the activities were, for both ambient $\mathrm{pHs}$, in the same range as those exhibited at $\mathrm{pH} 6.8$ in the wild-type context, and much higher than those observed at $\mathrm{pH} 4$ in the wild-type context. Thus, in the absence of a functional YIRim101p, no derepression of UAS2-driven expression occurred at $\mathrm{pH} 6.8$; in the presence of an active version of YIRim101p, the UAS2-driven expression was activated, at $\mathrm{pH} 4$, at levels similar to those observed under inducing conditions.

On MMAm, irrespective of the status of YlRIM101, the activity of hybrid promoters with 'UAS2A' or 'UAS2B' fragments was very low, actually lower than that of the control promoter (minimal pLEU2). Thus, the repression imposed on the minimal pLEU2 by the UAS2 on MMAm, where the preferred carbon and nitrogen sources are available, is insensitive to the YlRIM101 status and appeared to be dominant over the inducing effect exerted by a constitutively active form of YlRim101p.

\section{DISCUSSION}

The use of a reporter system allowed us to assess the transcriptional role of specific DNA sequences from the $\mathrm{pXPR2}$, outside their normal promoter context. Our data partly confirm and partly invalidate previous results (Blanchin-Roland et al., 1994). The presence of two UASs, presumably composed of several interacting elements, inferred from both deletion and footprinting experiments (Blanchin-Roland et al., 1994) was confirmed by the characteristics of the fragments analysed in the reporter system and by the reconstitution experiments.

In the UAS1 region, the 'UAS1A' (UAS ${ }_{\mathrm{RPG}}$-like) fragment alone exhibited the properties of a UAS, but the activity was enhanced by the presence of the adjacent region carrying imperfect repeats $\left(\mathrm{URS}_{\mathrm{CAR} 1}{ }^{-}\right.$-like sequences). However, the deletion of these repeats in the pXPR2 did not modify expression. The possibility remains that, in the whole $\mathrm{pXPR2}$, other sequences may compensate for the loss of the imperfect repeats by interacting with the core UAS1. Another possibility would be that the enhancement of UAS1 activity in the reporter system was not due to the imperfect repeats but to another sequence in the 'UAS1B' fragment, which remained undetected by DMS footprinting.

Concerning the UAS2, the interaction of both 'UAS2A' (decameric repeat) and 'UAS2C' (ABF1-like site) fragments appeared necessary for activity. These results essentially agree with those previously observed when performing deletions in $\mathrm{pXPR} 2$ (Blanchin-Roland et al., 1994): the deletion of the decameric repeat gave only $13-15 \%$ of residual activity in the three media. Thus, both reporter and deletion analyses showed that decamers were necessary for UAS activity. In contrast, the deletion of the overlapping ABF1- and GCN4-like sites in $\mathrm{pXPR2}$ gave $50 \%$ residual activity (BlanchinRoland et al., 1994), whereas we found here that the corresponding 'UAS2C' fragment was also necessary: it is possible that another sequence present in the $\mathrm{pXPR2}$ is able to interact with the decamers, and compensates in part for the loss of 'UAS2C'.

None of the GCN4-like sites of $\mathrm{pXPR2}$ seem to be implicated in its activity or regulation: their deletion, separately or together, led to no detectable change under the conditions tested. Moreover, the GCN4-like site of the UAS2 region had no effect in the reporter system, as shown by directed mutagenesis experiments. These results correlate with the fact that none of these sites are identical to the consensus of $S$. cerevisiae, and that their sequences are also different from each other. In the previous footprinting analysis (Blanchin-Roland et al., 1994), only one of these sites (in UAS1) was found to be clearly protected from DMS.

The reconstitution experiments confirmed that UAS1 and UAS2 were major determinants of the promoter activity. However, these experiments also showed that these UASs alone reconstituted grossly the regulation of the whole $\mathrm{pXPR2}$. This result was unexpected since previous deletion experiments led to the conclusion that none of the UAS regions were implicated in the regulation (the expression was greatly reduced, but still regulated by medium composition: Blanchin-Roland $e t$ al., 1994). This discrepancy can be explained by compensation effects from other sequences still present in the deleted promoter; it exemplifies the necessity of comparing the results obtained by different methods.

The UAS1 region was able to drive an enhancement of activity in all media (this effect was, however, low on MMAm, but increased with the fragment copy number). Thus, the UAS1 region is poorly sensitive to repressing conditions. It appears to drive a quasi-constitutive expression, especially when the number of 'UAS1B' fragments in the hybrid promoter was increased to 3 or 4 (Madzak et al., 1995). Such hybrid promoters, driving a high level of expression in various media, are interesting for heterologous protein expression and have been patented (Madzak et al., 1995).

In contrast, the repression by carbon and nitrogen sources and the $\mathrm{pH}$ regulation appeared to be linked to the UAS2 region. The 'UAS2A' fragment, associated with both of these regulations, encompasses two kinds of overlapping sequences: the decameric repeat, matching $A$. nidulans $\mathrm{PacC}$ binding sites, and two adjacent sequences similar to the URS $\mathrm{UAR}_{\mathrm{CA} 1}$ from $S$. cerevisiae. However, as shown in Fig. 3, only one copy of these latter sequences is identical to the $\mathrm{URS}_{\mathrm{CAR} 1}$ consensus and the other contains a mutation known to inactivate the site in $S$. cerevisiae (Luche et al., 1990). These two sequences are also in inverted orientation, like seven other homologous sequences found in the pXPR2 for which there is no evidence of possible implication in transcriptional regulation (data not shown, based on sequence homologies and deletion/ 
homologies to PacC site from $A$. nidulans

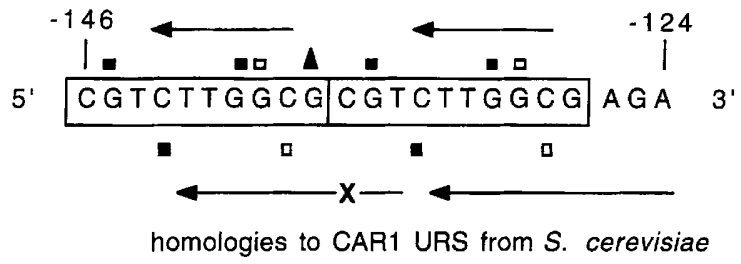

Fig. 3. Comparison of previous in vivo footprinting data for the UAS2 region with putative binding sites for known regulatory proteins. The sequence of the coding strand of $\mathrm{pXPR2}$, from position -146 to -124 , is shown. This sequence was included into both 'UAS2A' and 'UAS2B' fragments. The data obtained previously in DMS in vivo footprinting experiments were similar for cells grown on YPDm or MMAm media (Blanchin-Roland et al., 1994) and are summarized as follows: full and partial protections of specific guanines are indicated respectively by solid and open squares, above the sequence for the coding strand and below for the non-coding one; one hyperreactive site is indicated by the arrowhead. The decameric repeat is boxed. The homologies to binding sites for known regulatory factors from $S$. cerevisiae $\left(\mathrm{URS}_{\mathrm{CAR}_{1}}\right.$ ) or $A$. nidulans (PaCC) are indicated by the arrows. A mismatch with the consensus URS $_{\text {CAR1 }}$ sequence is indicated by the cross.

footprinting experiments from Blanchin-Roland et al., 1994). In contrast, the two sequences homologous to the $\mathrm{URS}_{\mathrm{CAR} 1}$ in the UAS1 region, which were partially protected in DMS footprinting (Blanchin-Roland et al., 1994) and presumably implicated in the UAS activity (data from reporter system) are identical to the consensus and in direct orientation. The results from DMS footprinting experiments performed on UAS2 (BlanchinRoland et al., 1994; see Fig. 3) have shown that: (i) the protection pattern is identical on the two decamers and covers them almost entirely; (ii) the $G$ nucleotide located between the PacC-like sequences corresponds to a hyperreactive site, as frequently found in the immediate vicinity of (and not inside) binding sites; (iii) the $5^{\prime}$ part of the first decamer is clearly protected, when it does not correspond to an $\mathrm{URS}_{\mathrm{CAR} 1}$ homology; (iv) the $3^{\prime}$ part of the second URS $\mathrm{CAR}_{\mathrm{CAR} 1}$ homology is clearly not protected, although it is identical to the consensus. The observed pattern was identical under inducing or repressing conditions.

On the basis of the above arguments, the implication of PacC-like sites in the different regulations mediated by the UAS2 appears probable, and that of $\mathrm{URS}_{\mathrm{CAR} 1}$-like sequences unlikely. Unless the DMS footprints were unable to distinguish between occupation of close, but distinct, sites, it seems possible that PacC-like sites are the target for different regulatory proteins, under different physiological conditions.

Results obtained from hybrid promoters, and with native $\mathrm{pXPR} 2$ carrying deletions in UAS2, strongly suggest that the repeated decamers are the targets of the UAS2 $\mathrm{pH}$ response. Since previous results (Lambert et al., 1997) suggested that they were bound by YlRim101p, a PacC homologue, we tested some of our constructions with hybrid promoters carrying 'UAS1B', 'UAS2A' or 'UAS2B' fragments, in different media, in different YlRIM101 contexts. Our results confirmed that the UAS1 activity was independent of the $\mathrm{pH}$-responsive regulation driven by YlRIM101 gene. The expression driven by UAS2 fragments appeared to be strongly dependent on the YlRIM101 context: the absence of a functional YlRim101p impaired UAS2-driven expression at $\mathrm{pH} 6 \cdot 8$, and a constitutively functional Cterminally truncated YlRim101p allowed us to obtain, regardless of ambient $\mathrm{pH}$, an activity similar to that observed under inducing conditions. These effects were observed with 'UAS2A' as well as with 'UAS2B', clearly implicating the decameric repeat (carrying PacC-like sites) in the YIRIM101-driven $\mathrm{pH}$-sensitive regulation. These results confirm a model of $\mathrm{pH}$ regulation in $Y$. lipolytica similar to that described in A. nidulans, where YlRim101p is activated by a C-terminal truncation at neutral-alkaline $\mathrm{pH}$, then binds to PacC-like sites, and thus activates the expression of the pXPR2 UAS2. The fact that, in the presence of preferred carbon and nitrogen sources, the UAS2-driven expression cannot be turned on by the C-terminally truncated YlRim101p, and even slightly represses basal promoter activity, suggests that a still unidentified regulatory protein is able to bind the decamer region under these conditions and to impair YlRim101p activation. This would agree with the footprinting data, indicating constant occupation of the PacC sites. Thus, in Y. lipolytica, in contrast to the situation in $A$. nidulans, and in agreement with that in P. chrysogenum (Suarez \& Peñalva, 1996), alkaline $\mathrm{pH}$ does not override the negative effect of a repressing carbon (and/or nitrogen) source.

The structure of $\mathrm{pXPR} 2$ UASs recalls what seems to be a general situation in $S$. cerevisiae, namely the association of a general ubiquitous transcriptional factor (ABF1, RAP1) and of factors specific for a small number of co-regulated promoters (Della Seta et al., 1990b; Kovari \& Cooper, 1991; Drazinic et al., 1996; GailusDurner et al., 1997; Devlin et al., 1991, and references therein).

Given the large evolutionary distance which separates Y. lipolytica from other yeasts (Barns et al., 1991), one would not necessarily predict that regulating sites (and transcriptional factors) would be conserved. Our work, however, suggests that those sequences and the corresponding binding factors may have been strongly conserved among ascomycetous yeasts. The cloning of YlRIM101, encoding a transcriptional factor with putative binding sites in UAS2 (PacC-like sites), which is implicated in a regulatory pathway similar to that described for A. nidulans, constitutes a strong argument in favour of this hypothesis. Another one is the homology found between all sequences from UAS regions implicated in transcriptional activity and consensus sites for known regulatory factors from other yeasts. The isolation of genes encoding these putative homologous factors will be pursued in our laboratory, permitting the testing of predictions from cis-acting sequences analysis. 


\section{ACKNOWLEDGEMENTS}

This work was supported by the Institut National de la Recherche Agronomique, by the Centre National de la Recherche Scientifique, and by a grant from the Pfizer Company (Groton, Connecticut, USA). R. R. Cordero Otero was supported by a grant from the Ministere de l'Agriculture.

\section{REFERENCES}

Arst, H. N., Bignell, E. \& Tilburn, J. (1994). Two new genes involved in signalling ambient $\mathrm{pH}$ in Aspergillus nidulans. Mol Gen Genet 245, 787-790.

Barns, S. M., Lane, D. J., Sogin, M. L., Bibeau, C. \& Weisburg, W. G. (1991). Evolutionary relationships among pathogenic Candida species and relatives. J Bacteriol 173, 2250-2255.

Barth, G. \& Gaillardin, C. (1996). Yarrowia lipolytica. In Nonconventional Yeasts in Biotechnology, a Handbook, pp. 313-388. Edited by K. Wolf. Berlin \& Heidelberg: Springer.

Blanchin-Roland, S., Cordero Otero, R. \& Gaillardin, C. (1994). Two upstream activation sequences control the expression of the XPR2 gene in the yeast Yarrowia lipolytica. Mol Cell Biol 14, $327-338$.

Boyer, H. W. \& Roulland-Dussoix, D. (1969). A complementation analysis of the restriction and modification of DNA in Escherichia coli. J Mol Biol 41, 459-472.

Cordero Otero, R. \& Gaillardin, C. (1996). Dominant mutations affecting expression of $\mathrm{pH}$-regulated genes in Yarrowia lipolytica. Mol Gen Genet 252, 311-319.

Davidow, L. S., O'Donnell, M. M., Kaczmarek, F. S., Pereira, D. A., De Zeeuw, J. R. \& Franke, A. E. (1987). Cloning and sequencing of the alkaline extracellular protease gene of Yarrowia lipolytica. $J$ Bacteriol 169, 4621-4629.

Della Seta, F., Treich, I., Buhler, J. M. \& Sentenac, A. (1990a). ABF1 binding sites in yeast RNA polymerase genes. J Biol Chem 265, 15168-15175.

Della Seta, F., Ciafre, S.-A., Marck, C., Santoro, B., Presutti, C., Sentenac, A. \& Bozzoni, I. (1990b). The ABF1 factor is the transcriptional activator of the $\mathrm{L} 2$ ribosomal protein genes in Saccharomyces cerevisiae. Mol Cell Biol 10, 2437-2441.

Devlin, C., Tice-Baldwin, K., Shore, D. \& Arndt, K. T. (1991). RAP1 is required for BAS1/BAS2- and GCN4-dependent transcription of the yeast HIS4 gene. Mol Cell Biol 11, 3642-3651.

Drazinic, C. M., Smerage, J. B., Lopez, C. \& Baker, H. V. (1996). Activation mechanism of the multifunctional transcription factor repressor-activator protein 1 (Rap1p). Mol Cell Biol 16, 3187-3196.

Fabre, E., Nicaud, J.-M., Lopez, M.-C. \& Gaillardin, C. (1991). Role of the proregion in the production and secretion of the Yarrowia lipolytica alkaline extracellular protease. I Biol Chem 266, 3782-3790.

Fantino, E., Marguet, D. \& Lauquin, G. J.-M. (1992). Downstream activating sequence within the coding region of a yeast gene: specific binding in vitro of RAP1 protein. Mol Gen Genet 236, $65-75$.

Franke, A. E., Kaczmarek, F. S., Eisenhard, M. E., Geoghegan, K. F., Danley, D. E., De Zeeuw, J. R., O'Donnell, M. M., Gollaher, M. G., Jr \& Davidow, L. S. (1988). Expression and secretion of bovine prochymosin in Yarrowia lipolytica. In Developments in Industrial Microbiology, vol. 29, pp. 43-57. Edited by G. Pierce. Amsterdam: Elsevier.
Gaillardin, C. \& Ribet, A.-M. (1987). LEU2 directed expression of $\beta$-galactosidase activity and phleomycin resistance in Yarrowia lipolytica. Curr Genet 11, 369-375.

Gailus-Durner, V., Chintamaneni, C., Wilson, R., Brill, S. J. \& Vershon, A. K. (1997). Analysis of a meiosis-specific URS1 site: sequence requirements and involvement of replication protein $A$. Mol Cell Biol 17, 3536-3546.

Guarente, L. (1995). Transcriptional coactivators in yeast and beyond. Trends Biochem Sci 20, 517-521.

Guarente, L. \& Bermingham-McDonogh, O. (1992). Conservation and evolution of transcriptional mechanisms in eukaryotes. Trends Genet 8, 27-32.

Hamsa, P. V. \& Chattoo, B. B. (1994). Cloning and growthregulated expression of the gene encoding the hepatitis $B$ virus middle surface antigen in Yarrowia lipolytica. Gene 143, 165-170.

Hanahan, D. (1985). Technics for transformation of Escherichia coli. In DNA Cloning: a Practical Approach, vol. I, pp. 109-135. Edited by D. M. Glover. Oxford: IRL Press.

Hanna-Rose, W. \& Hansen, U. (1996). Active repression mechanisms of eukaryotic transcription repressors. Trends Genet 12, 229-234.

Hill, D. E., Hope, I. A., Macke, J. P. \& Struhl, K. (1986). Saturation mutagenesis of the yeast his 3 regulatory site: requirements for transcriptional induction and for binding by GCN4 activator protein. Science 234, 451-457.

Hoffman, C. S. \& Winston, F. (1987). A ten-minute DNA preparation from yeast efficiently releases autonomous plasmids for transformation of Escherichia coli. Gene 57, 267-272.

Jung, S. Y., Yoo, H. Y., Kim, Y. H., Kim, J. \& Rho, H. M. (1995). The glucose-dependent transactivation activity of $A B F 1$ on the expression of the TDH3 gene in yeast. Curr Genet 27, 312-317.

Kovari, L. Z. \& Cooper, T. G. (1991). Participation of ABF1 protein in expression of the Saccharomyces cerevisiae CAR1 gene. J Bacteriol 173, 6332-6338.

Kunkel, T. A., Roberts, J. D. \& Zakour, R. A. (1987). Rapid and efficient site-directed mutagenesis without phenotypic selection. Methods Enzymol 154, 364-382.

Lambert, M., Blanchin-Roland, S., Le Louedec, F., Lepingle, A. \& Gaillardin, C. (1997). Genetic analysis of regulatory mutants affecting synthesis of extracellular proteinases in the yeast Yarrowia lipolytica: identification of a RIM101/pacC homolog. Mol Cell Biol 17, 3966-3976.

Luche, R. M., Sumrada, R. \& Cooper, T. G. (1990). A cis-acting element present in multiple genes serves as a repressor protein binding site for the yeast CAR1 gene. Mol Cell Biol 10, 3884-3895.

Madzak, C., Blanchin-Roland, S. \& Gaillardin, C. (1995). Upstream activator sequences and recombinant promoter sequences functional in Yarrowia and vectors containing them. European patent EP 0.747.484.A1 (application no. 95401322.3-2105).

Nicaud, J.-M., Fabre, E. \& Gaillardin, C. (1989a). Expression of invertase activity in Yarrowia lipolytica and its use as a selective marker. Curr Genet 16, 253-260.

Nicaud, J.-M., Fabre, E., Beckerich, J.-M., Fournier, P. \& Gaillardin, C. (1989b). Cloning, sequencing and amplification of the alkaline extracellular protease (XPR2) gene of the yeast Yarrowia lipolytica. J Biotechnol 12, 285-298.

Nicaud, J.-M., Fournier, P., La Bonnardière, C., Chasles, M. \& Gaillardin, C. (1991). Use of ars18 based vectors to increase protein production in Yarrowia lipolytica. J Biotechnol 19, 259-270. 
Ogrydziak, D. M., Demain, A. L. \& Tannenbaum, S. R. (1977). Regulation of extracellular protease production in Candida lipolytica. Biochim Biophys Acta 497, 525-538.

Orejas, M., Espeso, E. A., Tilburn, J., Sarkar, S., Arst, H. N. \& Peñalva, M. (1995). Activation of the Aspergillus PacC transcription factor in response to alkaline ambient $\mathrm{pH}$ requires proteolysis of the carboxy-terminal moiety. Genes Dev 9, $1622-1632$.

Ozcan, S., Leong, T. \& Johnston, M. (1996). Rgt1p of Saccharomyces cerevisiae, a key regulator of glucose-induced genes, is both an activator and a repressor of transcription. $\mathrm{Mol}$ Cell Biol 16, 6419-6426.

Park, C. S., Chang, C. C., Kim, J.-Y., Ogrydziak, D. M. \& Ryu, D. D. (1997). Expression, secretion and processing of rice $\alpha$-amylase in the yeast Yarrowia lipolytica. J Biol Chem 272, 6876-6881.

Ptashne, M. \& Gann, A. (1997). Transcriptional activation by recruitment. Nature 386, 569-577.

Ronne, H. (1995). Glucose repression in fungi. Trends Genet 11, 12-17.

Rubin-Bejerano, I., Mandel, S., Robzyk, K. \& Kassir, Y. (1996). Induction of meiosis in Saccharomyces cerevisiae depends on conversion of the transcriptional repressor Ume6 to a positive regulator by its regulated association with the transcriptional activator Ime1. Mol Cell Biol 16, 2518-2526.

Sinclair, D. A., Kornfeld, G. D. \& Dawes, I. W. (1994). Yeast intragenic transcriptional control: activation and repression sites within the coding region of the Saccharomyces cerevisiae LPD1 gene. Mol Cell Biol 14, 214-225.

Stargell, L. A. \& Struhl, K. (1996). Mechanisms of transcriptional activation in vivo: two steps forward. Trends Genet 12, 311-315.

Struhl, K. (1987). Promoters, activator proteins, and the mechanism of transcriptional initiation in yeast. Cell 49, 295-297.
Suarez, T. \& Peñalva, M. A. (1996). Characterization of a Penicillium chrysogenum gene encoding a PacC transcription factor and its binding sites in the divergent $p c b A B-p c b C$ promoter of the penicillin biosynthetic cluster. Mol Microbiol 20, 529-540.

Sussel, L. \& Shore, D. (1991). Separation of transcriptional activation and silencing functions of the RAP1-encoded repressor/activator protein. 1. Isolation of viable mutants affecting both silencing and telomere length. Proc Natl Acad Sci USA 88, 7749-7753.

Svetlov, V. V. \& Cooper, T. G. (1995). Review: Compilation and characteristics of dedicated transcription factors in Saccharomyces cerevisiae. Yeast 11, 1439-1484.

Tharaud, C., Ribet, A.-M., Costes, C. \& Gaillardin, C. (1992). Secretion of human blood coagulation factor XIIIa by the yeast Yarrowia lipolytica. Gene 121, 111-119.

Tilburn, J., Sarkar, S., Widdick, D. A., Espeso, E. A., Orejas, M., Mungroo, J., Peñalva, M. \& Arst, H. N. (1995). The Aspergillus $\mathrm{PacC}$ zinc finger transcription factor mediates regulation of both acid- and alkaline-expressed genes by ambient $\mathrm{pH}$. EMBO J 14, 779-790.

Trawick, J. D., Kraut, N., Simon, F. R. \& Poyton, R. O. (1992). Regulation of yeast COX6 by the general transcription factor ABF1 and separate HAP2- and heme-responsive elements. Mol Cell Biol 12, 2302-2314.

Vignais, M.-L., Huet, J., Buhler, J.-M. \& Sentenac, A. (1990). Contacts between the factor TUF and RPG sequences. $J$ Biol Chem 265, 14669-14674.

Xuan, J.-W., Fournier, P. \& Gaillardin, C. (1988). Cloning of the LYS5 gene encoding saccharopine dehydrogenase from the yeast Yarrowia lipolytica by target integration. Curr Genet 14, 15-21.

Received 13 July 1998; revised 5 October 1998; accepted 12 October 1998. 